\title{
APPlication OF THE MATHEMATiC Model TO EVALUATION OF WORKER'S WELL-BEING
}

\author{
Ruzena Kralikova, Laura Dzunova, Frantisek Koblasa, \\ Miriam Pinosova, Emil Wessely
}
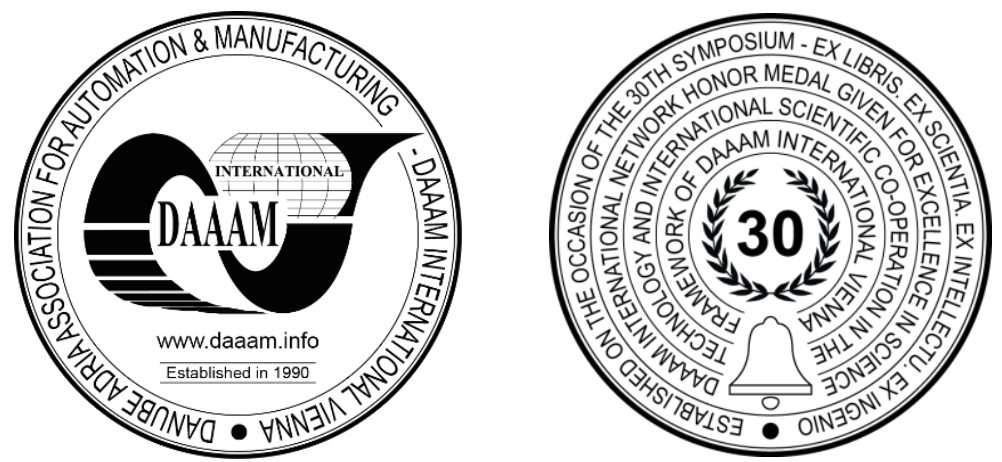

This Publication has to be referred as: Kralikova, R[uzena]; Dzunova, L[aura]; Koblasa, F[rantisek]; Pinosova, M[iriama] \& Wessely, E[mil] (2019). Application of the Mathematic Model to Evaluation of Worker'S Well-Being, Proceedings of the 30th DAAAM International Symposium, pp.0123-0130, B. Katalinic (Ed.), Published by DAAAM International, ISBN 978-3-902734-22-8, ISSN 1726-9679, Vienna, Austria DOI: $10.2507 / 30$ th.daaam.proceedings.016

\begin{abstract}
The article is aimed at assessing the possible negative impact of microclimate factors on work wellbeing, health and work productivity of the employees of the selected operation. In this paper, the effect of microclimate conditions such as air humidity, air flow and air temperature on workers comfort perception were studied. The research was carried out on a sample of 5 workers out of a total of 15 employees in the production hall. The aim of the research was to determine the level of influence of selected thermal parameters on the physical and mental well-being of employees. Participants were asked to complete a questionnaire designed to determine the level of perception of the impact of selected thermal parameters on the most vulnerable body parts. A mathematical model was used for a comprehensive assessment of the work environment's impact on employees. As the productivity of employees may also depend on employee satisfaction, research results can be used to improve the comfort of employees and to achieve better work performance.
\end{abstract}

Keywords: Employee; Indoor environment quality; Productivity; Thermal comfort; Workplace

\section{Introduction}

People in the workplace are exposed to several different factors (e.g. air temperature, radiant temperature, air velocity) that affect their perception of workplace comfort and can have a negative impact not only on their health but also on their work performance. Numerous experiments have been carried out to investigate the impact of thermal comfort parameters on employee satisfaction, health, productivity and others.

Fanger [1] was an expert in the field of thermal comfort and indoor environment, creating indoor air quality (IAQ) measurement units known as olf and decipol. He used climate chamber data to create an index to quantify the degree of discomfort for a given set of environmental conditions [2]. This index gives Predicted Mean Vote (PMV) to a large group of subjects by evaluating the state from cold to neutral to warm. The PVM is used to predict thermal comfort based on activity, clothing, ambient temperature, relative humidity, mean radiant temperature and air velocity. Fanger extended his concept to allow estimation of the predicted percent of dissatisfied people (PPD). The PPD increases as the predicted mean vote move away from zero in either direction. Wyon [4] demonstrated that IEQ such as thermal climate, humidity, 
and air quality has a significant effect on worker performance and health condition. He points out that improving health and productivity can be achieved by providing a better indoor environment, for example by improving the architecture of buildings. A study made by Fang et al. [5] showed that the impact of both temperature and humidity is highly significant on the perception of air quality. Wargocki et al. [6], Fang et al. [7] and Lan et al. [8] dealt with the influence of various factors affecting human comfort, for example, air quality and SBS (sick building syndrome) and their impact on productivity and health in indoor environments. In his study, he concluded that increasing the ventilation rate had a positive effect on health, comfort and productivity. Mendell et al. [9] pointed out that improving the indoor environment can help reduce work-related diseases and injuries such as respiratory infections, asthma or allergic reactions. And that by improving the indoor environment it is possible to reduce the economic consequences caused by the negative health effects of the indoor environment. Koehn et al. [10], Thomas et al. [11] conducted several investigations to determine the effect of temperature and relative humidity on construction productivity. A study made by Mohamed and Srinavin [12] examined the thermal environment/productivity forecasting models and finds that PMV-based model predictions are most consistent with the collected data. Hancher et al. [13], Rashid [14], Ibbs and Sun [15] studied the effects of hot or cold weather conditions on workflow, and labour productivity of construction workers. The response of the organism to thermal stress and its association with worker performance and health status was addressed in a study by Parson [16]. In his study, Parson also examined the causes of heat disorders, mechanism of heat stroke origin and human acclimatization ability. Paul and Taylor [17] and Newsham et al. [18] explored the inner quality of the environment and the comfort of people in green buildings. The results showed that green buildings give people a sense of higher comfort, environmental satisfaction, and satisfaction with thermal conditions. Research conducted by Xiong et al. [19] has proven better indoor air quality of green buildings in some investigated aspects than in conventional buildings. Thermal shocks are becoming more frequent and they affect the quality of life and human health (cardiovascular risk, allergic reactions and infectious diseases) [20].

In general, it is a combination of different physical, chemical, biological and psychological factors that can negatively affect workers but all of the above-mentioned studies have proven a significant impact of IEQ (Indoor Environmental Quality) on the human physical and mental well-being [3]. Health problems can seriously affect workers concentration and performance, which may result in low productivity and quality of work. Due to increasing pressure on employees to achieve the highest performance in the shortest time possible, it is necessary to provide workers with conditions that will not restrict their full potential [21]. Therefore, it is important that the company management measure employees' satisfaction with IEQ in the workplace regularly and should take actions to ensure optimal conditions. The inspiration may be this research, which is using the questionnaire and mathematical model described below, to identify weaknesses in selected IEQ parameters. The required values of IEQ parameters for thermal comfort can be found in the relevant standards e.g. ANSI / ASHRAE Standard 55, EN-15251 or ISO 7730 standard [22].

\section{Indoor environment quality parameters}

Microclimatic conditions [23] are an important component of the working environment. Among the most important and most influencing factors for microclimate in the workplace are:

- The operative temperature $-\mathrm{t}_{\mathrm{o}}\left[{ }^{\circ} \mathrm{C}\right]$ is the uniform temperature of a closed black space in which there would be an exchange of the same amount of heat between flow and radiation between humans and the environment as in a real inhomogeneous environment.

- Relative humidity $-\mathrm{R}_{\mathrm{h}}[\%]$ indicates the degree of saturation of air by water evaporation. It is defined by the ratio of the water evaporation density in the air and in the moist air saturated with water evaporation at the same temperature and pressure.

- Air flow velocity - is a quantity determined by the flow direction and direction, characterizing the air movement in space.

- Dry air temperature $\mathrm{t}_{\mathrm{a}}\left[{ }^{\circ} \mathrm{C}\right]$ - ambient air temperature in the environment.

- Average radiant temperature $\mathrm{t}_{\mathrm{r}}\left[{ }^{\circ} \mathrm{C}\right]$ and radiation intensity I [W.m-2] from machines, heaters, material, etc..

Figure 1 shows the human perception of thermal comfort depending on the air flow velocity and air temperature, with or without local control of airspeed and with different clothing insulation (winter clothing $=1.0$ clo and summer clothing $=0.5$ clo) at an activity of 1.1 met (metabolic equivalent) which represents the light intensity activity (i.e., sitting) at humidity ratio 0.01 [24]. The graph depicts still acceptable air velocity and operating temperature values, but the perception of thermal comfort is highly subjective and it also depends on many other factors than those abovementioned e.g. sex, health, mental well-being, age, pregnancy.

The graph in Figure 2 illustrates the relationship between relative humidity and temperature and its effect on the formation of viruses and mould. It is known that higher humidity and air temperature intensifies thermal sensation and reduces perspiration and evaporation of the body's capacity, which can lead to lack of sweating and the inability of the body to cool itself. 


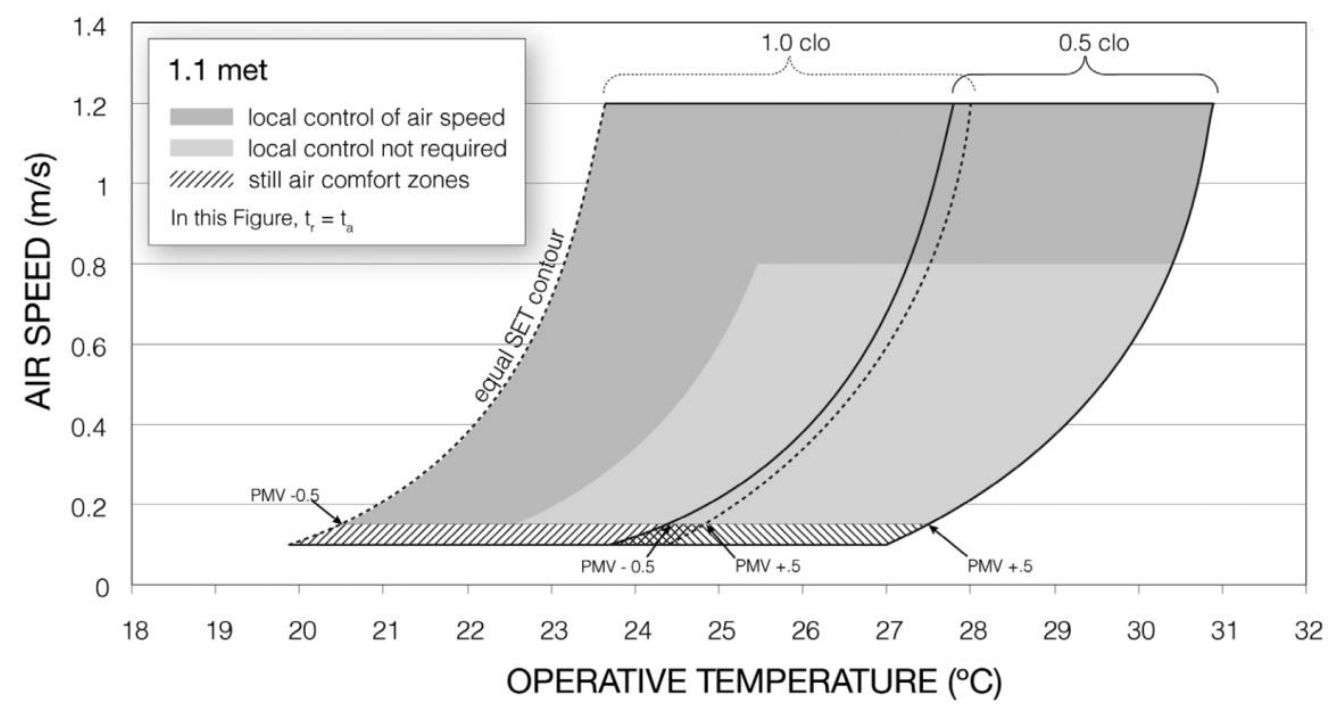

Fig. 1. Acceptable range of temperature and air speed for comfort zone [24]

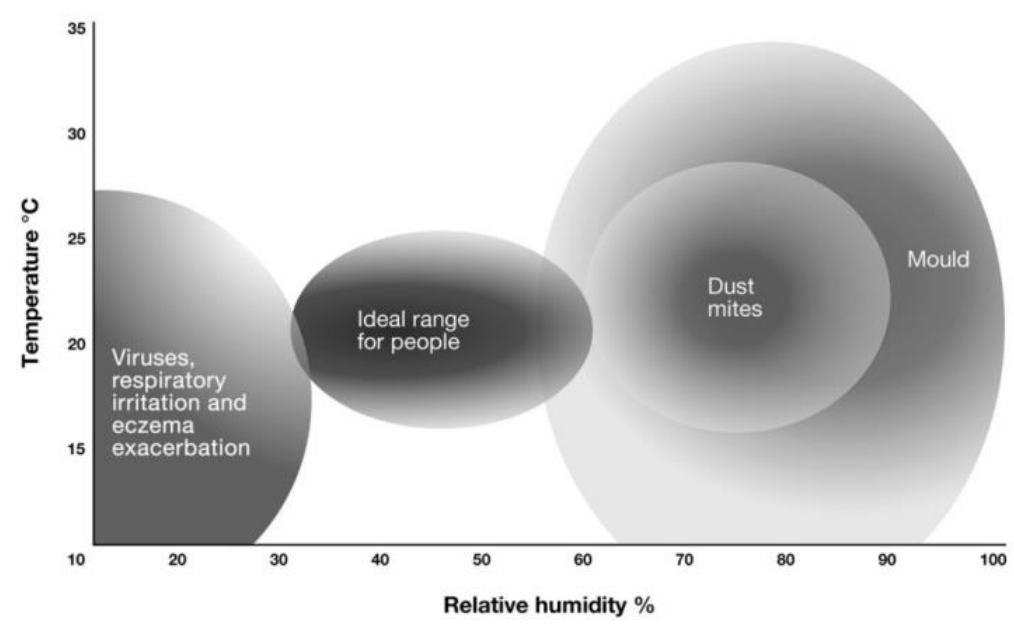

Fig.2. Influence of temperature and relative humidity on thermal comfort [25]

If the thermal comfort factors (e.g. air humidity, air temperature, air flow) have adverse results of the measured values it may be a cause of unpleasant feelings, irritability, non-concentration, and can negatively affect productivity and quality of the work [26]. Under certain conditions, especially if the values are too high or low, they may even pose a health risk to the worker. The meaning and further explanation of terms relating to microclimate factors are described in Decree No. 99/2016 [23].

The optimal microclimate conditions for a particular type of work are determined based on the heat production of the worker's body, which is determined by the manner and intensity of the activity being carried out, whereas: thermal production of organism = energy expenditure. According to the total energy expenditure, the individual work activities are classified in the individual working classes [23]. In the case of workplaces where it is not possible to ensure optimal conditions for the worker, the employer is obliged to implement special measures to protect the health of the worker. For example, workplaces with high or low ambient temperatures (ironworks, cold stores etc.).

\section{Research description}

To determine the state of perception of the parameters of microclimate factors by workers and to assess their impact, research was carried out in a company that manufactures metal structures, cut parts and cylindrical products. Cut cylindrical gears were made by the hobbing method using CNC machine tools which can successfully be used in the case of mass production also [27]. Another aim of the research was also to determine which parameters most significantly affect the discomfort of employees. The production hall, where the research was carried out, has an area of about $200 \mathrm{~m}^{2}$ and 15 employees. 
Using mathematical statistics methods, an original mathematical model [28, 29] was developed, which allows to express the effect of the negative effect of microclimate factors and to evaluate the workload of employees by microclimatic conditions during working hours ( 8 hours). The total load $(\mathrm{Z})$ can be expressed as the result of the action of the individual load factors using the formula:

$$
\mathrm{Z}=Z_{1}+Z_{2}+Z_{j}+\cdots+Z_{n}
$$

where: $\mathrm{Z}_{1}, \mathrm{Z}_{2}, \mathrm{Z}_{3}, \ldots \mathrm{Z}_{\mathrm{n}}$ are load factors.

Each of the factors contributes to the same weight or rate to the total load. It is, therefore, possible to assume that the load factor $Z_{1}$ will contribute to the total load by the value of the indicator $\alpha_{1}$, load factor $Z_{2}$ by the measure $\alpha_{2}$, to the load factor $Z_{n}$ with the measure $\alpha_{n}$. This condition must be met:

$$
\alpha_{1}+\alpha_{2}+\alpha_{j}+\cdots+\alpha_{n}=1
$$

where: $\alpha_{j} \in(0,1)$ and $\alpha_{1}, \alpha_{2}, \alpha_{j} \ldots \alpha_{n}$ - the coefficients of the severity of the impact of individual factors.

These coefficients characterize the rate of load on the human body. To assess the significance of these coefficients, the following condition shall be followed:

$\alpha_{\mathrm{j}}$ close to $0=>$ insignificant impact of $\mathrm{Z}_{\mathrm{j}}$,

$\alpha_{\mathrm{j}}$ close to $1 \Rightarrow$ significant impact of $\mathrm{Z}_{\mathrm{j}}$.

The values of the individual coefficients of gravity are determined by the point method, which is based on the allocation of points ( 0 to 10$)$ for each type of partial load $\left(\mathrm{Z}_{\mathrm{j}}\right)$ and the individual organs of the human organism (Ti) in a particular work activity. Whether the total workload of a particular working environment is the result of the action of the individual load factors $Z_{1}, Z_{2}, \ldots, Z_{n}$, and let this working environment affect the organs of the human organism $T_{1}, T_{2}$, $\ldots, \mathrm{T}_{\mathrm{m}}$, where $\mathrm{m}, \mathrm{n} \in \mathrm{N}$ according to the following scheme [25]:

- The effect of the load factor $Z_{1}$ on the body organ $T_{1}$ is evaluated by the point value $b_{1}=1$, by the body value $T_{2}$ by the point value $b_{2}=1$, to the body organ $T m$ with the point value $b_{m}=1$, following the above standards and regulations.

- Subsequently, the procedure is analogous and the effect of the load factor $\mathrm{z}_{2}$ on the body organ $\mathrm{T}_{1}$ is evaluated by the point value $b_{1}=2$, on the body organ $T_{2}$ by the point value $b_{2}=2$ to the body organ Tm with the point value $b_{m}=2$.

In this way it is possible to get a matrix:

$\mathrm{B}=\left(\mathrm{b}_{i j}\right)$

where: $b_{i j}$ - assigned load point value $Z_{j}$ on the human body part $T_{i}, i=1,2, \ldots, m$

The principle of the described point method and the determination of the severity coefficients for the individual load factors of a given working environment is shown in the following table (Tab.1).

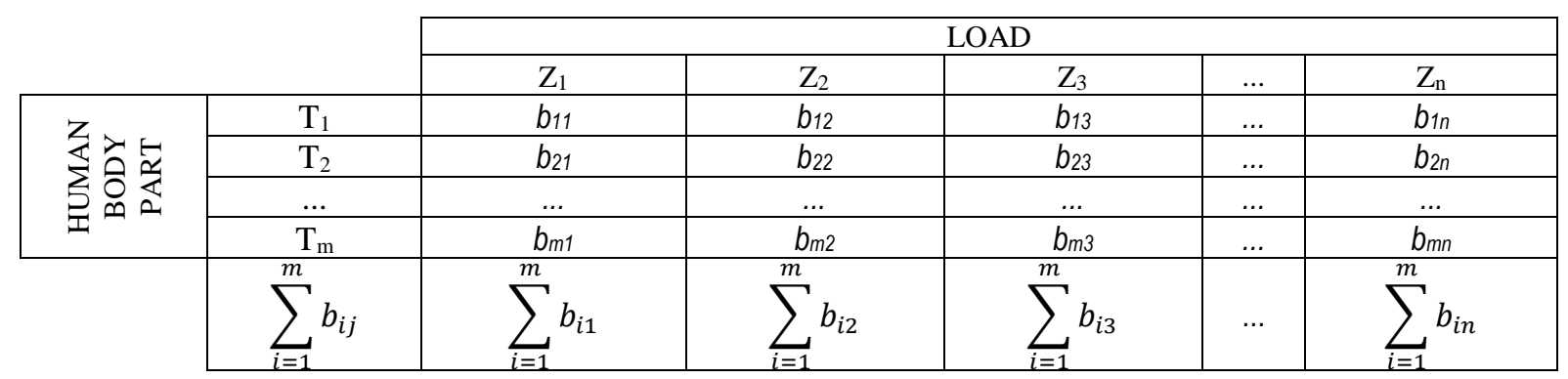

Table 1. The point method principle [25]

All three parts of the system are equally important and influence each other, and therefore it is necessary to look at them as a whole and pay enough attention to every single one of them. In the literature, the work environment is often characterized as a set of physical, chemical, biological, social and cultural factors that may affect a person at the workplace, Figure 2. The calculation model presents the formula: 
$\alpha_{1}=\frac{\sum_{i=1}^{m} b_{i 1}}{\sum_{j=1}^{n} \sum_{i=1}^{m} b_{i j}}, \alpha_{2}=\frac{\sum_{i=1}^{m} b_{i 2}}{\sum_{j=1}^{n} \sum_{i=1}^{m} b_{i j}}, \alpha_{j}=\frac{\sum_{i=1}^{m} b_{i j}}{\sum_{j=1}^{n} \sum_{i=1}^{m} b_{i j}} \ldots \alpha_{n}=\frac{\sum_{i=1}^{m} b_{i n}}{\sum_{j=1}^{n} \sum_{i=1}^{m} b_{i j}}$

The described model for the determination of complex human organism load during continuous work enables to use of the method of objective as well as subjective evaluation in the point method for determining the coefficients of severity. To obtain information about employees' feelings due to the microclimate parameters of the workplace environment, the point method of evaluation was used, while the required data were obtained based on a questionnaire survey filled by 5 workshop employees.

The point method results of the questionnaire survey are displayed in Tab. 2.

\begin{tabular}{|c|c|c|c|c|}
\hline \multirow{2}{*}{\multicolumn{2}{|c|}{ Worker 1}} & \multicolumn{3}{|c|}{ LOAD } \\
\hline & & Air flow & Air temperature & Air humidity \\
\hline \multirow{5}{*}{ 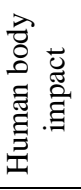 } & $\mathrm{T} 1$ & 2 & 8 & 4 \\
\hline & $\mathrm{T} 2$ & 2 & 6 & 5 \\
\hline & T3 & 2 & 6 & 3 \\
\hline & $\mathrm{T} 4$ & 3 & 2 & 1 \\
\hline & T5 & 8 & 1 & 1 \\
\hline \multicolumn{2}{|c|}{ SUMA } & 17 & 23 & 14 \\
\hline \multirow{2}{*}{\multicolumn{2}{|c|}{ Worker 2}} & \multicolumn{3}{|c|}{ LOAD } \\
\hline & & Air flow & Air temperature & Air humidity \\
\hline \multirow{5}{*}{ 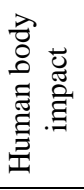 } & $\mathrm{T} 1$ & 3 & 7 & 3 \\
\hline & $\mathrm{T} 2$ & 3 & 6 & 3 \\
\hline & $\mathrm{T} 3$ & 4 & 6 & 4 \\
\hline & $\mathrm{T} 4$ & 5 & 1 & 1 \\
\hline & T5 & 8 & 0 & 0 \\
\hline \multicolumn{2}{|c|}{ SUMA } & 23 & 20 & 11 \\
\hline \multirow{2}{*}{\multicolumn{2}{|c|}{ Worker 3}} & \multicolumn{3}{|c|}{ LOAD } \\
\hline & & Air flow & Air temperature & Air humidity \\
\hline \multirow{5}{*}{ 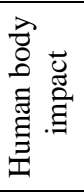 } & $\mathrm{T} 1$ & 3 & 7 & 4 \\
\hline & $\mathrm{T} 2$ & 3 & 7 & 4 \\
\hline & $\mathrm{T} 3$ & 3 & 7 & 4 \\
\hline & $\mathrm{T} 4$ & 5 & 1 & 1 \\
\hline & T5 & 7 & 0 & 0 \\
\hline \multicolumn{2}{|c|}{ SUMA } & 21 & 22 & 13 \\
\hline \multirow{2}{*}{\multicolumn{2}{|c|}{ Worker 4}} & \multicolumn{3}{|c|}{ LOAD } \\
\hline & & Air flow & Air temperature & Air humidity \\
\hline \multirow{5}{*}{ 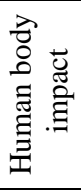 } & $\mathrm{T} 1$ & 2 & 7 & 4 \\
\hline & $\mathrm{T} 2$ & 3 & 6 & 4 \\
\hline & $\mathrm{T} 3$ & 3 & 7 & 3 \\
\hline & $\mathrm{T} 4$ & 5 & 2 & 1 \\
\hline & T5 & 8 & 0 & 1 \\
\hline \multicolumn{2}{|c|}{ SUMA } & 21 & 22 & 13 \\
\hline \multirow{2}{*}{\multicolumn{2}{|c|}{ Worker 5}} & \multicolumn{3}{|c|}{ LOAD } \\
\hline & & Air flow & Air temperature & Air humidity \\
\hline \multirow{5}{*}{ 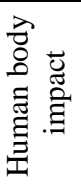 } & $\mathrm{T} 1$ & 2 & 8 & 5 \\
\hline & $\mathrm{T} 2$ & 3 & 6 & 5 \\
\hline & $\mathrm{T} 3$ & 2 & 6 & 3 \\
\hline & $\mathrm{T} 4$ & 5 & 1 & 0 \\
\hline & T5 & 7 & 1 & 0 \\
\hline \multicolumn{2}{|c|}{ SUMA } & 19 & 22 & 13 \\
\hline
\end{tabular}

Table 2. Workers individual load perception - point method

Where: $\mathrm{T}_{1}$ - Perspiration, $\mathrm{T}_{2}$ - Breathing difficulty, $\mathrm{T}_{3}$ - Mental wellbeing, $\mathrm{T}_{4}$ - Cervical and lumbar spine, $\mathrm{T}_{5}-$ Inner ear. 


\section{Evaluation of results and discussion}

The aim of the research was to evaluate the impact of microclimate parameters (temperature, air flow, air humidity) on the wellbeing of employees. The presented mathematical model (6) was used for the complex evaluation of the microclimate parameters of the workplace. The evaluation results are presented in Tab. 3 and Tab.4.

\begin{tabular}{|c|c|c|c|c|}
\hline \multirow{2}{*}{\multicolumn{2}{|c|}{$\begin{array}{c}\text { ALL } \\
\text { WORKERS }\end{array}$}} & \multicolumn{3}{|c|}{ LOAD } \\
\hline & & Air flow & Air temperature & Air humidity \\
\hline \multirow{5}{*}{ 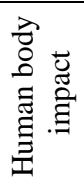 } & $\mathrm{T} 1$ & 12 & 37 & 20 \\
\hline & $\mathrm{T} 2$ & 14 & 31 & 21 \\
\hline & T3 & 14 & 32 & 17 \\
\hline & $\mathrm{T} 4$ & 23 & 7 & 4 \\
\hline & T5 & 38 & 2 & 2 \\
\hline \multicolumn{2}{|c|}{ SUMA } & 101 & 109 & 64 \\
\hline
\end{tabular}

Table 3. The overall perception of load by all workers - point method

Complex load calculation according (4):

$\alpha_{1}=\frac{\sum_{i=1}^{m} b_{i 1}}{\sum_{j=1}^{n} \sum_{i=1}^{m} b i j}, \alpha_{2}=\frac{\sum_{i=1}^{m} b_{i 2}}{\sum_{j=1}^{n} \sum_{i=1}^{m} b i j}, \alpha_{3}=\frac{\sum_{i=1}^{m} b_{i 3}}{\sum_{j=1}^{n} \sum_{i=1}^{m} b i j}$

Where:

$$
\left(\alpha_{1}+\alpha_{2}+\alpha_{3}\right) * 100=100[\%]
$$

\begin{tabular}{|l|c|c|c|}
\hline \multicolumn{2}{|l|}{ Environmental Indicator } & Numeric value & Percentage value \\
\hline $\boldsymbol{\alpha}_{\mathbf{1}}$ & Air flow velocity & 0,3686 & $36,86 \%$ \\
\hline $\boldsymbol{\alpha}_{\mathbf{2}}$ & Air temperature & 0,3978 & $39,78 \%$ \\
\hline $\boldsymbol{\alpha} \mathbf{3}$ & Air humidity & 0,2336 & $23,36 \%$ \\
\hline \multicolumn{2}{|c|}{ Sum of the factors } & 1 & $100 \%$ \\
\hline
\end{tabular}

Table 4. Value expression of factors and percentage of the impact of factors on the workers

Five of a total of 15 employees were involved in the survey. From the values obtained it is possible to analyze the influence of temperature, humidity and air flow on individual parts of the organism. It follows from the calculation that air temperature was a factor that had the greatest negative impact on the employees with load $\alpha_{2}=39,78 \% \%$. According to the results of the chosen method, the temperature has a considerable impact on excessive sweating at work, excessive breathing and, last but not least, it has a significant impact on workers well-being, concentration and performance. The graphical representation of the results is shown in Figure 3.

The air flow load coefficient is only a slightly lower than temperature load coefficient with its value of $\alpha_{1}=36,86 \%$. This value is relatively high in a workplace with permanent employee movement and can affect not only their comfort but also their health when working for eight hours. The fact that it is not clear if employees use, appropriate working clothes, headgear and other protective equipment can affect research results. In this case, it is necessary to train staff and ensure that they use the available protective equipment. The air flow in the production hall harms the unprotected auditory organs, the cervical and the lumbar part of the spine. Workers complained about problems with their middle ear and pain in the cross caused by air flow velocity. Such burden on the body can cause long-term health complications for workers and at the same time their incapacity for work, so measures should be taken to protect workers from the negative effects of the air flow. The difference between these factors is insignificant but the effect of air temperature can be considered as more severe as the effect of air flow rate [30]. In the summer months, air temperatures can be even higher, and in the absence of air conditioning and inadequate air exchange, employees are likely to feel sick. The research results also show that the least burdensome parameter is air humidity with its load coefficient $\alpha_{3}=23,36 \%$. Looking at the results of the point method in assessing the impact of humidity on workers, it is obvious that most body parts are not negatively affected by it. Potentially increased humidity in the workplace, according to the staff, manifests itself in breathing problems, excessive sweating and mental well-being.. The average value of point 1, in areas of the body such as the ear and upper / lower spine, suggests a low impact of air humidity on these parts. 


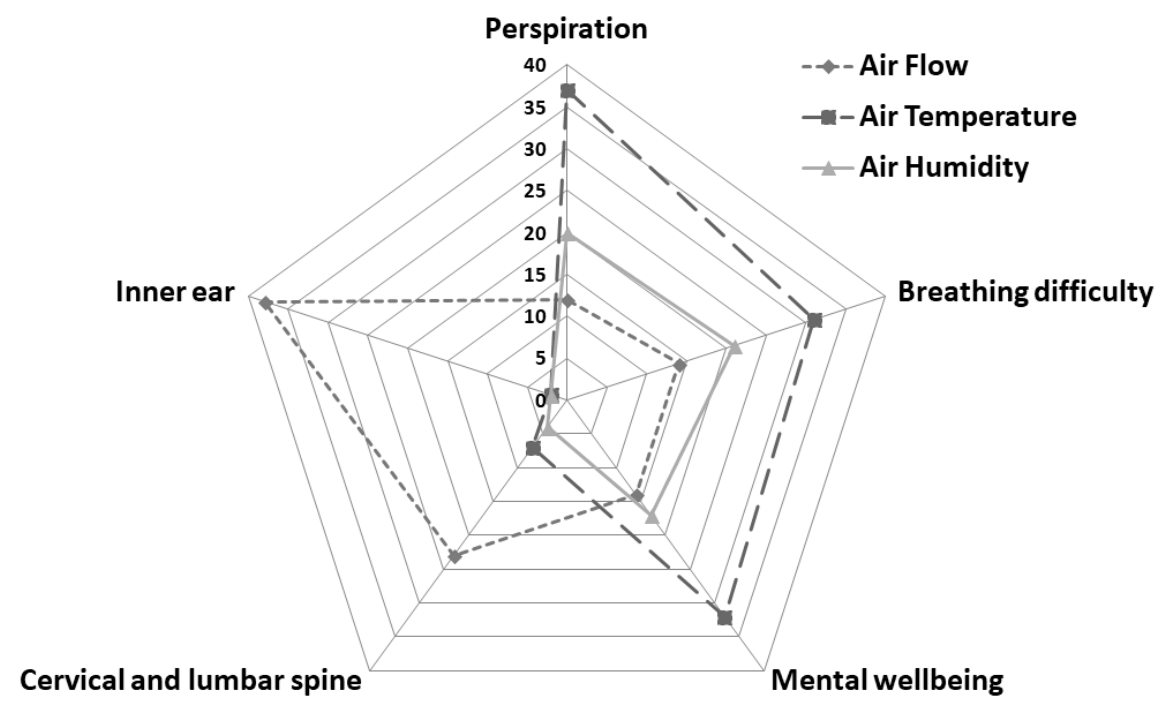

Fig. 3. Influence of examined factors on human body of workers

\section{Conclusion}

In this article, the effect of microclimate parameters at the comfort and health of workers was studied by using a questionnaire and mathematical model. The results of the research showed that the well-being and health of the employees of the selected company were most influenced by the temperature and airflow at the workplace. Participants complained about excessive perspiration and breathing difficulty due to high ambient temperature and discomfort in the middle ear and spinal cord due to draft. A healthy, suitable and comfortable work environment is an important indicator of the cultural maturity of organizations. Man is the most sensitive element of the production process and his cognitive abilities are irreplaceable, so it is necessary to create optimum working conditions for workers to fully exploit their work potential. Based on the survey's results, it would be appropriate to modify the indoor environmental quality conditions (reduce draft and ambient temperature) in the workplace. It would also be advisable to redesign ventilation technology and install an air conditioning system both with regard to energy saving. As the research mentioned in the introduction of the article points to a significant link between productivity and thermal comfort, by reducing the negative effect of selected parameters it is possible that the company will achieve higher profits.

Based on the interim results of the questionnaire survey, future research will deal with methods of monitoring individual performance by specialized personal sensors and monitors concerning environmental criteria. The environmental criteria against which the monitoring results are compared may vary depending on the circumstances in the workplace and some professional judgment is required. The main objective should be to determine which criteria are to be used in determining what physical activities a worker can perform in the working environment. This is important to take into account in the context of many ongoing experiments related to performance and environmental factors that affect health and behaviour in terms of physical activity.

\section{Acknowledgments}

The paper was elaborated within the framework of the projects: KEGA 032TUKE-4/2018 "Intensification of education and information processes in engineering for quality of the environment", and KEGA 041TUKE-4/2018 which are solved at Department of process and environmental engineering, Technical University of Kosice and as a part of project solved at the Technical University of Liberec No 21278 „Optimization of manufacturing systems, 3D technologies and automation".

\section{References}

[1] Fanger, P.O. (1970). Thermal Comfort. Analysis and applications in environmental engineering. Danish Technical Press. Copenhagen, p. 244.

[2] Fanger, P.O. (1988). Olf and decipol - the new units for perceived air quality. ASHRAE Journal, pp. 35-38.

[3] Kralikova, R. \& Wessely, E. (2016) Lighting quality, productivity and human health, Annals of DAAAM and Proceedings of the International DAAAM Symposium, pp. 59-65. DOI: 10.2507/27th.daaam.proceedings.009.

[4] Wyon, D.P. (2004). The effects of indoor air quality on performance and productivity. Indoor air, 14(7), pp. 92-101.

[5] Fang, L., Clausen, G., \& Fanger, P.O. (1998). Impact of temperature and humidity on the perception of indoor air quality. Indoor air, 8(2), pp. 80-90. 
[6] Wargocki, P., Wyon, D.P., Baik, Y.K., Clausen, G., \& Fanger, P.O. (1999). Perceived air quality, sick building syndrome (SBS) symptoms and productivity in an office with two different pollution loads. Indoor air, 9(3), pp.165179.

[7] Fang, L., Wyon, D.P., Clausen, G., \& Fanger, P.O. (2004). Impact of indoor air temperature and humidity in an office on perceived air quality, SBS symptoms and performance. Indoor air ,14, pp. 74-81.

[8] Lan, L., Wargocki, P., Wyon, D.P., \& Lian, Z. (2011). Effects of thermal discomfort in an office on perceived air quality, SBS symptoms, physiological responses, and human performance. Indoor air, 21(5), pp. 376-390.

[9] Mendell, M.J., Fisk, W.J., Kreiss, K., Levin, H., Alexander, D., Cain, W.S.,...Wallingford, K.M. (2002). Improving the health of workers in indoor environments: priority research needs for a national occupational research agenda. Am J Public Health, 292(9), pp.1430-1440. doi:10.2105/ajph.92.9.1430.

[10] Koehn, E., \& Brown, G. (1985). Climatic effects on construction. Journal of Construction Engineering and Management,111(2). https://doi.org/10.1061/(ASCE)0733-9364(1985)111:2(129).

[11] Thomas, H.R., \& Yiakoumis, I. (1987). Factor Model of Construction Productivity. Journal of Construction Engineering and Management, 113(4). https://doi.org/10.1061/(ASCE)0733-9364(1987)113:4(623).

[12] Mohamed, S., \& Srinavin. K. (2005). Forecasting labor productivity changes in construction using the PMV index. International Journal of Industrial Ergonomics,35(4), pp. 345-351. https://doi.org/10.1016/j.ergon.2004.09.008

[13] Hancher, D.E., \& Abd-Elkhalek, H.A. (1998). The effect of hot weather on construction labor productivity and costs. Cost Engineering; Morgantown, 40(4), pp. 32-36.

[14] Rashid, H.A. (2015). Weather Effect on Workflow, and Labor Productivity of Construction Plant. Civil and Environmental Research, 7(11).

[15] Ibbs,W., \& Sun, X. (2017). Weather's Effect on Construction Labor Productivity. Journal of Legal Affairs and Dispute Resolution in Engineering and Construction,9(2). https://doi.org/10.1061/(ASCE)LA.1943-4170.0000212.

[16] Parsons, K. (2009) Maintaining health, comfort and productivity in heat waves, Global Health Action, 2(1). https://doi.org/10.3402/gha.v2i0.2057.

[17] Paul, W.L., \& Taylor P.A. (2008). A comparison of occupant comfort and satisfaction between a green building and a conventional building. Building and Environment, 43(11), pp. 1858-1870. https://doi.org/10.1016/j.buildenv.2007.11.006.

[18] Newsham, G. R., Birt, B.J., Arsenault, Ch., Thompson, A.J., Veitch, J.A., Mancini, S, Burns, G.J. (2013) Do 'green' buildings have better indoor environments? New evidence. Building Research \& Information, 41(4), pp $415-434$. https://doi.org/10.1080/09613218.2013.789951.

[19] Xiong, Y., Krogmann, U., Mainelis, G., Rodenburg, L.A., Andrews, C.J. (2015). Indoor air quality in green buildings: A case-study in a residential high-rise building in the northeastern United States. Journal of Environmental Science and Health Part A Toxic/Hazardous Substances \& Environmental Engineering, 50(3), pp. 225-242.

[20] Kralikova,R. , Koblasa, F. (2018) Approaches to the evaluation of workshop microclimate conditions MM Science Journal, 2018(June), pp. 2397-2400. DOI: 10.17973/MMSJ.2018_06_2017107.

[21] Kati Kõrbe K., Tauno O.(2014). Smart Health Care Monitoring Technologies to Improve Employee Performance in Manufacturing. Annals of DAAAM and Proceedings of the International DAAAM Symposium. 25(1). Procedia Engineering 100 ( 2015 ) 826 - 833. DOI: 10.1016/j.proeng.2015.01.437.

[22] Kralikova, R., 2018. The methodology and survey on energy saving and greening illumination for application in the automobile industry, IOP Conference Series: Materials Science and Engineering 2018. ISSN: 17578981 DOI: $10.1088 / 1757-899 X / 393 / 1 / 012081$

[23] Decree no. 99/2016 Coll. (2016) Decree of the Ministry of Health of the Slovak Republic on details of health protection against heat and cold loads at work. Retrieved from: http://www.epi.sk/zz/2016-99

[24] ANSI/ASHRAE Standart 55 (2010). Thermal Environmental Conditions for Human Occupancy. American Society of Heating, Refrigerating and Air Conditioning Engineers. Atlanta.

[25] Sensitive choise. (2015, April 8). Indoor humidity levels. Retrieved from https://www.sensitivechoice.com/indoorhumidity/

[26] Koblasa, F., Sirova, E. \& Kralikova, R.: The Use of Process Thinking in the Industrial Practice - Preliminary Survey. Technical Gazette. 26 (3). Pages: 786-792. DOI: 10.17559/TV-20150617135306.

[27] Gołębski, R., \& Ivandić, Ž. (2018). Analysis of Modification of Spur Gear Profile. Technical Gazette, 25 (2), 643 648. https://doi.org/10.17559/TV-20171018100732.

[28] Kralikova,R. , Wessely, E.: (2018). Impact of the environmental factors and its effects on productivity and health. Annals of DAAAM and Proceedings of the International DAAAM Symposium. 29(1). Pages 0119-0124. $\square$ DOI: 10.2507/29th.daaam.proceedings.016.

[29] Rusko, M. et al.: (2017): The management tools and methods application of the organization to environmental protection. Annals of DAAAM and Proceedings of the International DAAAM SymposiumVolume 27, Issue 1, 2016, Pages 283-288. DOI: 10.2507/27th.daaam.proceedings.042.

[30] Rusko, M., Pavlova, I., Vanova, J. \& Kralikova, R. (2017) Connectivity of quality management systems and environmental management systems. Annals of DAAAM and proceedings of the international DAAAM symposium. pp. 1213-1220. ISSN: 17269679 DOI: 10.2507/28th.daaam.proceedings. 169 . 